\title{
Erratum to “On DFT Molecular Simulation for Non-Adaptive Kernel Approximation" [Advances in Materials Physics and Chemistry Vol. 4 No. 6 (June 2014) 105-115]
}

\author{
Maharavo Randrianarivony \\ Virtual Material Design, Fraunhofer Institute for Algorithms and Scientific Computing SCAI, Schloss \\ Birlinghoven, Sankt Augustin, Germany \\ Email: maharavo.randrianarivony@scai.fraunhofer.de
}

Received 30 April 2014; accepted 4 June 2014; published 11 June 2014

Copyright (C) 2015 by author and Scientific Research Publishing Inc.

This work is licensed under the Creative Commons Attribution International License (CC BY).

http://creativecommons.org/licenses/by/4.0/

$$
\text { (c) (i) } 0 \text { pen Access }
$$

The original online version of this article (Randrianarivony, M. (June 2014) On DFT Molecular Simulation for Non-Adaptive Kernel Approximation. Advances in Materials Physics and Chemistry, Vol. 4 No. 6, 105-115. http://dx.doi.org/10.4236/ampc.2014.46013) did not contain any acknowledgment. The author wishes to add the following acknowledgements:

Acknowledgements: This work was partially supported by Eurostars Project E!6935 funded by German Federal Ministry of Education and Research. 